\title{
Increasing Stimulation Parameters Relieves Acquired Eyelid Apraxia after Deep Brain Stimulation of the Subthalamic Nucleus
}

\author{
Akın Akakın ${ }^{1 *}$, Baran Yılmaz ${ }^{2}$, Nazıre Afsar ${ }^{1}$ and Turker Kılıc ${ }^{1}$ \\ ${ }^{1}$ Department Of Neurosurgery, Bahcesehır Unıversıty School Of Medıcıne, Turkey \\ ${ }^{2}$ Department Of Neurology, Bahcesehır Unıversıty School Of Medıcıne, Turkey
}

\begin{abstract}
Acute ischemic stroke is one of the prominent roots of mortality and morbidity all over the world. Core ischemic regions, penumbral regions and extra penumbral regions occur proximal or distal to arterial occlusion where the margins of ischemia are hyperemic with either one, minimal or no parenchymal damage. Electroencephalography (EEG) and single photon emission computed tomography (SPECT) remains the investigative practices that let economical, noninvasive learning of physiological and pathological actions in the human brain in acute ischemic stroke. Mutually these procedures may detect different patterns resonant of severity, prognosis, and secondary injury allied to acute ischemic stroke. Also, these readings can be intensely linked to cerebral metabolism which is sensitive to ischemia. This review summarizes the EEG and SPECT changes and their limitations in monitoring patients with acute ischemic stroke patients.
\end{abstract}

\section{Introduction}

Deep brain stimulation (DBS) of the subthalamic nucleus (STN) provides an effective evidence-based symptomatic surgical treatment for advanced stages of Parkinson's disease (PD) [1,2]. Optimal hardware programming can be challenging in some cases, as side effects may interfere with stimulation parameters required for sufficient control of motor symptoms [3,4]. Eyelid Apraxia, defined as inability to voluntarily initiate opening of eyelids [5], is one of limiting adverse effects which has been reported in 1.8 to $30 \%$ of the patients after STN DBS and management of the eyelid apraxia event was mainly relied on medical treatment [6-8].

Here, we present a case of PD patient exhibiting clinical features of eyelid apraxia after STN DBS, which had improved well by adjusting the stimulation parameters with sufficient control of motor symptoms without changing medical regime.

\section{Case}

A 80 years-old women with Parkinson Disease was planned to undergo bilateral STN-DBS. After magnetic resonance imaging (MRI), stereotactic frame (Integra CRW) was placed onto the patient at the day of the surgery and Computer Tomography (CT) was done. Later, both images were auto-fused to target the anterior lateral side of left STN and right STN by image fusion programme (Atlas Integra Software). We have done bilateral micro-recording test (Alfa Omega Micro Recording System) and during macro stimulation test, we have observed some facial and eye muscles effects. After that we decided to pull microelectrode $1 \mathrm{~mm}$ above to target. Then, we selected our targets for both sides and sent DBS electrode lead (St. Jude Medical $614940 \mathrm{~cm}$ lead) bilaterally to STN anterior lateral sides. Finally, we implanted impulse generator (St. Jude Medical Libra XP 6644) and connected to DBS electrode leads.

The day after the surgery when the implanted impulse generator was switched on, we observed that the patient was not able to open her eyes. There was no change in the preoperative drug regime and it was resumed. As the situation of the patient did not change, we decided to start adjusting stimulation parameters.

During the first postoperative week, the pulse width, frequency and amplitude of impulse generator was increased stepwise (Table 1). At the end of the 1st week after the surgery, we changed the stimulation parameters until very remarkable differences was observed and she was already able to open her eyes and look at around consciously.

\section{Discussion}

The bilateral subthalamic nucleus stimulation has some known side effects as hypophonia, dysarthria, dyskinesia and eyelid apraxia. Eye lid apraxia is a non-paralytic motor abnormality characterized by difficulty in initiating opening of the eyelids [7,8]. Premotor control of lid-eye coordination by extrapyramidal and mesencephalic circuitries has been suggested and dopaminergic involvement was further substantiated by analysis of blinking rates in patients with PD [9]. Regarding the pathogenesis of eyelid apraxia, the distance from subthalamic nucleus to optic tracts, substantia nigra and red nucleus is only $3 \mathrm{~mm}$ which is very close. This region can be affected during micro recording and stimulation period of the surgery [10].

Postoperative eyelid apraxia incidence has been reported between $1.8 \%$ and $31 \%[6,8]$. Regarding the management of eyelid apraxia seen

\begin{tabular}{|c|c|l|l|l|l|c|}
\hline Daily Trials & Stimulation Parameters & DAY-1 & DAY-3 & DAY-5 & DAY-6 & DAY-7 \\
\hline \multirow{3}{*}{ TRIAL-1 } & P.W. $(\mathrm{uS})$ & 65 & 98 & 117 & 117 & 117 \\
\cline { 2 - 7 } & Freq. $(\mathrm{Hz})$ & 130 & 130 & 140 & 150 & 170 \\
\cline { 2 - 7 } & Amp. $(\mathrm{mA})$ & 2.0 & 3.0 & 4.0 & 4.0 & 4.0 \\
\hline \multirow{3}{*}{ TRIAL-2 } & P.W. $(\mathrm{uS})$ & 98 & 117 & 117 & 117 & 117 \\
\cline { 2 - 7 } & Freq. $(\mathrm{Hz})$ & 130 & 130 & 150 & 160 & 180 \\
\cline { 2 - 7 } & Amp. $(\mathrm{mA})$ & 2.5 & 4.0 & 4.0 & 4.0 & 4.0 \\
\hline
\end{tabular}

Table 1: Stimulation Parameters From the Postoperative Day-1 To Day-7.

*Corresponding author: Akın Akakın, Bahcesehır Unıversıty School Of Medıcıne Neurosurgery, Medıcal Park Hastanesı E-5 Uzeri 23 Nisan Sok. Merdivenkoy Istanbul, 34742 Turkey, Tel: +905353162693; E-mail: drbaranylmz2013@gmail.com

Received December 19, 2013; Accepted February 24, 2014; Published March 05, 2014

Citation: Akakın A, Yılmaz B, Afsar N,Kılıc T (2014) Increasing Stimulation Parameters Relieves Acquired Eyelid Apraxia after Deep Brain Stimulation of the Subthalamic Nucleus. J Neurol Neurophysiol 5: 191. doi:10.4172/21559562.1000191

Copyright: @ 2014 Akakın A, et al. This is an open-access article distributed under the terms of the Creative Commons Attribution License, which permits unrestricted use, distribution, and reproduction in any medium, provided the original author and source are credited. 
Citation: Akakın A, Yılmaz B, Afsar N,Kılıc T (2014) Increasing Stimulation Parameters Relieves Acquired Eyelid Apraxia after Deep Brain Stimulation of the Subthalamic Nucleus. J Neurol Neurophysiol 5: 191. doi:10.4172/2155-9562.1000191

either during the course of the disease or after STN DBS, increasing levodopa dosage, botulinum toxin A injections and adjusting stimulation parameters are all proposed as effective methods [6,11-14].

In our report, eyelid apraxia of the patient improved well by increasing stimulation parameters together with sufficient control of tremor and no change in bradykinesia or rigidity. Without any change the medical regime and/or any invasive intervention, the stimulation parameters had been adjusted and increased throughout the first postoperative week. All combinations of contacts are described well in Table 1 . The patient could open her eyes and look at around consciously at the end of the first week after increasing the frequency values. In the long-term follow-up, we planned not to keep the stimulation parameters at these values. However, in our first attempt to decrease the frequency, the symptoms re-emerged. Hence, we postulated that the frequency was the determinant in each adjustment trial periods. The expected battery life is 6 year long from the day set with; Pulse Width: $91 \mathrm{uS}$ Frequency: $180 \mathrm{~Hz}$, Amplitude: $3.0 \mathrm{~mA}$ parameters bilaterally.

\section{Conclusion}

When dealing with eyelid apraxia after STN DBS, postoperative modification of stimulation parameters may be beneficial as a way of treatment before attempting other management trials.

\section{References}

1. Kleiner-Fisman G, Herzog J, Fisman DN, Tamma F, Lyons KE, et al. (2006) Subthalamic nucleus deep brain stimulation: summary and meta-analysis of outcomes. Mov Disord 21: S290-304.

2. Krack P, Batir A, Van Blercom N, Chabardes S, Fraix V, et al. (2003) Fiveyear follow-up of bilateral stimulation of the subthalamic nucleus in advanced Parkinson's disease. N Engl J Med 349: 1925-1934.

3. Deuschl G, Herzog J, Kleiner-Fisman G, Kubu C, Lozano AM, et al. (2006) Deep brain stimulation: postoperative issues. Mov Disord 21: S219-237.
4. Weiss D, Wächter T, Breit S, Jacob SN, Pomper JK, et al. (2010) Involuntary eyelid closure after STN-DBS: evidence for different pathophysiological entities. J Neurol Neurosurg Psychiatry 81: 1002-1007.

5. Goldstein Je, Cogan Dg (1965) Apraxia Of Lid Opening. Arch Ophthalmol 73 155-159.

6. Tommasi G, Krack P, Fraix V, Pollak P (2012) Effects of varying subthalamic nucleus stimulation on apraxia of lid opening in Parkinson's disease. J Neurol 259: 1944-1950.

7. Beric A, Kelly PJ, Rezai A, Sterio D, Mogilner A, et al. (2001) Complications of deep brain stimulation surgery. Stereotact Funct Neurosurg 77: 73-78.

8. Umemura A, Oka Y, Yamamoto K, Okita K, Matsukawa N, et al. (2011) Complications of subthalamic nucleus stimulation in Parkinson's disease. Neurol Med Chir (Tokyo) 51: 749-755.

9. Agostino R, Bologna M, Dinapoli L, Gregori B, Fabbrini G, et al. (2008) Voluntary, spontaneous, and reflex blinking in Parkinson's disease. Mov Disord 23: 669-675.

10. Priori A, Ardolino G, Marceglia S, Mrakic-Sposta S, Locatelli M, et al. (2006) Low-frequency subthalamic oscillations increase after deep brain stimulation in Parkinson's disease. Brain Res Bull 71: 149-154.

11. Fuss G, Spiegel J, Magnus T, Moringlane JR, Becker G, et al. (2004) Improvement of apraxia of lid opening by STN-stimulation in a 70 -year-old patient with Parkinson's disease. A case report. Minim Invasive Neurosurg 47: 58-60.

12. Strecker K, Meixensberger J, Schwarz J, Winkler D (2008) Increase of frequency in deep brain stimulation relieves apraxia of eyelid opening in patients with Parkinson's disease: case report. Neurosurgery 63: E1204.

13. Umemura A, Toyoda T, Yamamoto K, Oka Y, Ishii F, et al. (2008) Apraxia of eyelid opening after subthalamic deep brain stimulation may be caused by reduction of levodopa. Parkinsonism Relat Disord 14: 655-657.

14. Kanazawa M, Shimohata T, Sato M, Onodera O, Tanaka K, et al. (2007) Botulinum toxin A injections improve apraxia of eyelid opening without overt blepharospasm associated with neurodegenerative diseases. Mov Disord 22: 597-598. 